\title{
Fixation and Needle Fixation
}

\author{
Scott Welsh ${ }^{1}$ Victoria University
}

\begin{abstract}
Terminology is important in psychoanalysis. The words and language used by psychoanalysts and psychoanalytic theorists to describe particular phenomena are governed by the therapeutic or interpretative context in which they are used. The word 'projection', for example, means one thing in the ordinary social world and quite another for the psychoanalyst, patient or theorist. The same can be said of fixation and some addiction theorists are beginning to question the use of the term needle fixation because of its implied unconscious content. This paper proposes that needle fixation can be understood and articulated as a bona-fide fixation through the use of contemporary and traditional psychoanalytic theorists. The problem of language and terminology, identified by Fraser et al., (2004) no longer applies and the term 'needle fixation' stands both in its psychoanalytic usage as arrested development and the contemporary reference by addicts and addiction theorists to compulsive injection as needle fixation.
\end{abstract}

\section{Introduction}

Terminology is important in psychoanalysis. The words and language used by psychoanalysts and psychoanalytic theorists to describe particular phenomena are governed by the therapeutic or interpretative context in which they are spoken. For the contemporary reader, the word 'projection', for example, means one thing in the ordinary social world and quite another for the psychoanalyst, patient or theorist. (Freud, 1895, p.109; Klein, 1946) The same can be said of fixation in relation to a bona-fide, unconscious fixation and needle fixation. Some addiction theorists are beginning to question the use of the term 'needle fixation' because of its implied unconscious content (Fraser et al., 2004). I propose that needle fixation can be understood and articulated as a bona-fide fixation through the use of contemporary and traditional psychoanalytic theorists. I address the problem of language and terminology, identified by Fraser et al. (2004) needle fixation stands both in its psychoanalytic usage as arrested development at an unconscious stage and the contemporary reference by addicts and addiction theorists to compulsive injection.

This paper, then, not only explores the world of the injecting drug user through the use of psychoanalysis, it raises questions of language and authority. Who can say what fixation is? If we are to believe Fraser et al., (2004) then it seems psychoanalysis has a monopoly on the term and, if we are to use it, we must play by their rules. We must define needle fixation as an unconscious fixation for the term to have any value and ultimately for the

${ }^{1}$ Correspondence concerning this article should be addressed to Scott Welsh, Victoria University. E-mail: scott.welsh2@live.vu.edu 
phenomenon to be recognised and treated. The importance of language and its usage cannot be understated here.

\section{Literature Review}

Pates and McBride define needle fixation as the compulsion to inject regardless of the substance. (McBride, Pates \& Arnold 2005, p. 47) The debate regarding their views on needle fixation, however, has elicited no response from psychoanalysis. This is in spite of controversy over whether this term, originating in psychoanalysis where it carries a specific meaning, is being used appropriately in the context of debates on needle use (Fraser et al., 2004, p.73). Thus, while psychoanalysis has contributed to the literature on addiction, there are only a handful of contributions on needle fixation. This is to the detriment of an informed discussion of Pates and McBride's claims that compulsive injection represents a fixation as well as the counter claims of Fraser, Hopwood, Treloar and Brenner regarding the psychoanalytic origins of the term. Some of the historical observations made by McBride in the context of his discussion of intravenous use indicate a negative reaction from the establishment to the use of the needle. This includes one instance in which a medical doctor from the nineteenth century personally discontinued the practice of injecting because of what appears to have been a fear of patients exhibiting signs of needle fixation (McBride, Pates \& Arnold 2005). The same is true of Latimer and Goldberg, and there is evidence of moral panic over what appears to be instances of needle fixation in some of the experiences implicitly but effectively documented by Burroughs in the novel Junky (Latimer \& Goldberg, 1981; Burroughs, 1953).

In one of the articles in Cocaine Papers, Freud describes a young doctor, a friend who arrives at his door one night with bloody arms, wounded as a result of compulsive injecting (Byck, 1972, p.188). Before the invention of psychoanalysis, Freud seems to be describing the phenomenon of needle-fixation well before the notion of 'needle-fixation' was introduced. This term, first used by addicts themselves, has become a subject of recent controversy among addiction theorists because the term has emerged from addicts' experience and not from theoretical claims. I show however, how a psychoanalytic understanding of needle fixation can contribute to this debate.

A recent study by Fraser et al. of a sample of methadone users who had injected the syrup compelled Pates and McBride to declare that these addicts were motivated by the phenomenon of needle fixation (Pates \& McBride, 2005). In a subsequent publication, McBride, Pates and Arnold define needle fixation as 'the compulsion to inject', while in an article titled Needle Foucation, they describe a plethora of colourful characters, among them Burroughs, and their particular relationship with the needle (Pates \& McBride 2005; Latimer \& Goldberg 1981). The notion of needle fixation has been contested by their colleagues who reject the fact that there is something compulsive about injecting. For instance, Fraser et al. claim instead that "needle fixation can be understood as a product of discourse, and as such, as both fact and fiction." (Fraser et al., 2004). Unlike Rowe, who argues in The Feel of The Steel that needle fixation can be explained by an anticipation of the affect of the substance, I argue that injection is a metaphor for the satisfaction of unconscious urges (Rowe, 2009). Fraser et al., in a subsequent response to Pates and McBride's claims, caution that because needle fixation "encompasses very different behaviours, is in some ways limiting, and has negative connotations, careful consideration should be given before it is accepted as a useful and therapeutic tool" 
(Fraser et al., 2004, p. 1). However, McBride, Pates and Arnold speculate that it is a useful concept because a shared understanding exists between addicts and the agencies that treat them. (McBride, Pates \& Arnold 2007) Fraser et al. claim that needle fixation is the product of discourse encompassing both fact and fiction, advising we proceed with caution (Fraser et al., 2005).

The idea of needle fixation is present in Burroughs' Junky, which presents itself as fiction but provides as much insight into the problem as many theoretical works through a firsthand examination of addict culture. The term 'needle fixation' however, is yet to be considered in a psychoanalytic context.

Addiction has long been associated with masturbation; Freud made the link and Latimer and Goldberg (1981), citing Bulkley, a doctor of divinity in 1840, writes,

Drug abuse was merely a certain consequence of self-abuse, the substituting of one sensual vice for another. Masturbation usually followed the same abominable behaviour pattern. It is usually continued until the unfolding reason and conscience open the victim's eyes to the true nature of his habit. (Latimer \& Goldberg 1981, p.193)

Whilst this may appear to be on par with the superstitious notion that masturbation causes blindness and Bulkley's claim seems to be directed more toward the habit of masturbation than addiction, the connection between masturbation and addiction is of particular importance.

In Subject of Addiction (2002) Rik Loose claims that masturbation and addiction represent a single phenomenon or two phenomena that share certain similar properties, and appeals to Freud on masturbation to construct a psychoanalytic theory of addiction. As Loose points out, Freud saw masturbation as the greatest of all addictions (Loose 2002). Loose's psychoanalytic theory of addiction is based on the notion that addiction offers the complete satisfaction masturbation fails to provide. He explains that addicts suffer from a disturbance at the mirror stage due to libidinal content in the encounter with the parental other, who helps the infant stand so that he/she can view him/herself in the mirror. This creates a specific dissatisfaction from the universal practice of masturbation, causing them to seek out something else in pursuit of complete satisfaction.

For addicts, masturbation fails to provide complete satisfaction because the libidinal encounter with the parental other at the mirror stage offers the illusion of complete satisfaction. Drawing on Loose's explanation of addiction, I will engage with the disputed phenomenon of needle fixation. As I will show, injection represents too much of what Lacan calls 'the real' while needle fixation can be understood as a fixation on the libidinal encounter with the parental other at Lacan's mirror stage of development (Loose 2002). Whilst Loose seems to propose that addiction to substances and activities such as gambling is an attempt by addicts to self-soothe a disturbance at the mirror stage, I 
propose that the contemporary addict's non-medical, compulsive self-injection constitutes a fixation at the mirror stage.

According to Lacan, the mirror stage occurs at a moment in the human subject's life when his or her body is experienced as being in bits and pieces as it strives toward selfrecognition or identification with its own image in the mirror. Loose, who addresses addiction to substance and gaming and characterizes the human subject of the addict as suffering from an invasion by 'the real' due to a trauma at the mirror stage, refers to the 'libidinal encounter' with the parental other at this unconscious stage (Loose, 2002, p.184). Injection is symbolic of this libidinal encounter. The satisfaction enjoyed by the addict who compulsively injects, regardless of substance, is repeating this unconscious libidinal encounter and, I claim, that this constitutes an unconscious fixation. The process of self injection can be conceived as a form of masturbation that better replicates the unconscious desire for intercourse with the parental other and the accompanying "insufficient orgasm" experienced by addicts during masturbation (Loose, 2002). The needle fixator is suffering from a repetition of this invasion of the real in the form of a libidinal encounter with the parental other at the mirror stage. This invasion of the real can manifest itself as insufficient orgasm in the universal practice of masturbation (Loose, 2002, p.184). Therefore, perhaps the addict requires something else, something beyond masturbation to achieve the satisfaction the ordinary human subject takes for granted, satisfaction ordinarily brought about by the orgasm achieved through the practice of masturbation. Loose seems to claim that the addict experiences a disturbance at the mirror stage causing this insufficient orgasm. Needle fixation, addiction to the needle or injection, can be understood as a fixation or arrested development at this stage, particularly a fixation on the libidinal content, what Loose calls the incestuous oneness with mother, or the parental other (Loose, 2002). The possible symbolic value of injection is represented in the infantile sexual drives of the incomplete human subject. Hence, what is the self injector doing when he self-injects? I propose he is satisfying infantile sexual drives.

There is a significant body of work based on the self-medication hypothesis. Due to the chemical foundations of this theory, that is, the emphasis on 'substance' to self-medicate, there is no space within it for speculation on a form of addiction to what McBride, Pates and Arnold call the mechanism of the needle (Kantzian et al., 2008). Since needle fixation is not a form of self-medication, there is no place for it in psychoanalytic discourse. Khantzian's article proposing the self-medication hypothesis, the dominant addiction theory in psychoanalysis, divides addicts according to their choice of substance. McBride, Pates and Arnold's work, on the other hand, is concerned with addiction to the needle; the mechanism.

Around the AIDS crisis in the 1980s and 1990s, the question of needle use became important in fields of cultural studies and sociology, sometimes examining the meaning of the needle. For example, Manderson observes that "the fetishization of the objects of drug use makes the law and the drug addict far more alike than often thought". (Manderson, 1995, p. 783) Howard and Borges, Feldman and Biernacki, Paige and Smith seem, in some measure, to recognise the importance of the needle in drug using culture, without directly acknowledging or identifying the idea of needle fixation. (Howard \& Borges, 1971; Paige \& Smith, 1990). However, these are not psychoanalytic theorists and they do not seek to address the issue of fixation with the needle, its meaning or content. More recently, Pates has expanded on his research with McBride in The 
Development of a Psychological Theory of Needle Fixation where he refers to the work of Levine, who he says, may have pioneered this contentious notion in his Needle Freaks: Compulsive Self-injection by Drug Users in 1974 (Pates \& Gray, 2009; Levine, 1994) As Pates observes, the concept is contentious because the idea that one might become addicted to a mechanism, a physical object is foreign to a discourse based on chemical hypotheses such as that of self-medication. Levine's publication occurs in the discourse around the same time E. M. Brechter claims that addicts use the needle for the orgasmic rush and that the slow acting methadone could counteract this compulsion (Brechter, 1972). In my view, Pates' attempts to claim that needle fixation is a genuine problem for the field of addiction have failed to convince his colleagues because of his emphasis on compulsive injection rather than unconscious fixation. Fraser et al. recognize that the term 'fixation' is a psychoanalytic term. Curiously, they appeal to this fact to argue against the existence of the phenomenon of needle fixation. Below, I engage with both McBride, Pates and Arnold and with Fraser et al., using the psychoanalytic writings of Loose and Lacan, as well as Freud's concept of fixation, to show how 'needle fixation' can be understood as a phenomenon with an unconscious cause.

There have been some recent contributions on the subject in psychoanalytic journals, and a number of contributions from psychoanalysts have appeared in addiction journals. Valentine and Fraser have contributed psychoanalytic insights to the debate with a detailed study of the connection between types of drug use and ritual pleasures (Valentine \& Fraser, 2008). Their claims are based on empirical studies and descriptions of drug users with an emphasis on social status and poverty. This component of their claim, that is, the social status of drug users, very much resembles a reference to Freud by Lacan. ${ }^{2}$ However, Valentine and Fraser's study is too empirical, too overtly social, to be connected with my claim, which emphasizes the unconscious fixation of the needlefixator at Lacan's mirror stage.

A stray comment by Freud has been used to explain the enjoyment of injection as displaced male sexual aggression (Freud, 1900). Hopper claims that the enjoyment of self-injection is due to the unconscious homosexual fantasies the injector is entertaining while injecting (Hopper, 1976). This can be linked to the Freudian idea of displaced male sexual aggression in an inverted form. Hopper's thesis is consistent with the connection Loose makes between masturbation and addiction. If homosexual fantasies are being entertained while injecting as Hopper claims, this may indicate a form of masturbation; the practice of injecting replacing masturbation. However, while Hopper attributes unconscious motivations to self-injecting and Loose proposes an unconscious cause for addiction, neither Hopper nor Loose directly address the question of needle fixation. Hopper's theory cannot be described as a theory of needle fixation in the same way that Freud sees fixation because, whilst Hopper speculates on possible unconscious motivations for injection, he does not directly identify an unconscious stage at which the human subject is detained. The idea that the human subject is detained at an unconscious stage is crucial to Freud's concept of fixation. Like McBride and Pates and perhaps Loose, Hopper does not address the idea of fixation. Rather, Hopper's claim is a small component of a more general theory of addiction based on the idea of latent homosexuality.

\footnotetext{
${ }^{2}$ This is comparable with Lacan's comment on Freud where he claims that "those jouissances which are forbidden by conventional morality are nevertheless perfectly accessible and accepted by certain people" (Lacan, 1959-1960, p. 200).
} 
Much has been said in recent years about the problem of transgressive intravenous drug use, however, most of the literature seeks sociological explanations for phenomena associated with the needle. For example, the British Journal of Addiction adheres to an epidemiological approach to illicit drug use (Giovanni et al., 1992). The problem of needle-sharing has brought with it an entire body of research including examinations of the social circumstances of drug users and endless attempts to sterilize' the drug users environment through theoretical means. However, the idea of approaching drug addiction through epidemiology is rejected by Pates who claims ethnography is a more useful tool of analysis (McBride, Pates \& Arnold, 200). It is, however, the case that epidemiologists frequently employ ethnographic methods. For example, a study of the transmission networks for HIV utilised a conversational method at a truck-stop with female sex workers. (Nyamuryekung'e et al., 1997) The new discipline of drug studies is also driven by the epidemiological approach. Much of the literature is concerned about the problem of needle sharing, such as Howard and Borges in Needle sharing in the Haight exploring the psychological function or problem of needle-sharing (which perhaps explains the epidemic idea because physical disease is spread through the use of the needle). However, there is very little literature that speculates on what might drive the addict to share needles, and no psychoanalytic material on an unconscious cause for this behaviour which might lead to the use of the term 'needle fixation'. I claim that this problem of needle-sharing and its psychological motivations may include a sexual metaphor. I claim, however, that the enjoyment of injecting the other is merely a vicarious enjoyment of injecting oneself which I claim is the origin of needle fixation.

Julie Miller has speculated that the needle represents a transitional object, that is, a replacement for the first object of the mother. Miller examines an aetiology of heroin addiction from the perspective of object relations (Miller 2002). Her focus is on the needle as a transitional object in patients who have experienced early childhood deprivation and separation trauma. She claims that the needle represents an object that replaces the closeness of the mother's breast on the face concluding that "for the heroin addict the transitional object is transformed into pathological process" (Miller, 2002, p. 193). Miller does not directly state that the heroin addict has needle fixation. However, by claiming the needle acts as a transitional object that is later transformed into a pathological process, she implies that the enjoyment of injection is based around a fixation on such a transitional object caused by arrested development at this infantile stage. Loose's use of Lacan's mirror stage to explain the general phenomenon of addiction furthers Miller's claims by identifying a precise moment in an unconscious stage, the libidinal encounter at the mirror stage and that this allows for an understanding of needle fixation as a genuine unconscious problem requiring the attention of psychoanalysis. Miller's work, like much of the literature on addiction, places too much emphasis on the substance rather than the needle. Whilst she presents a viable claim regarding an unconscious cause for injection, she makes this claim in the context of a theory on heroin addiction, thereby emphasizing substance. On the other hand, McBride, Pates and Arnold make claims regarding injection, and particularly needle fixation, without offering an unconscious cause for either. My research has a relationship with both Miller and McBride but with particular attention to the term 'needle fixation' in a psychoanalytic context. Miller's claim that the needle is a transitional objectis curious. The transitional object, according to Winnicott, is an object that replaces the closeness of the infant to the mother (Winnicott, 1953). This idea is not particularly prevalent in the process of injection described by McBride in Injecting Illicit Drugs. For the three 
elements of body, substance and mechanism at the injection site do not include any reference to an object that might be considered a transitional object. Freud's description of Dr Taylor however, goes somewhere toward assigning the needle the quality of a transitional object.

His hypodermic syringe with which he gave himself the cocaine, had been taken away and no form of substitute was allowed. He was about as rational as a man who had been taking whisky or opium freely and about as nervous as one from whom these agents had been suddenly taken. (Byck 1975 quoting Freud 1887, p.189)

Notice that in this description, it is not merely the injection that the subject craves but a particular closeness with the hypodermic syringe. In this way, the syringe that has given the self-injection in Freud's description, acquires the quality of a transitional object. This however, is not Miller's claim. Rather, she equates heroin with mother's milk and in this sense reverts to the almost universal emphasis on substance rather than the mechanism of injection or the fixation on the needle and its use (Miller, 2002, p.293).

A recent collection titled Understanding Abnormal Behaviour (Sue, Sue and Sue, 2006) identifies the phenomenon of the addicts' needle habit, observing the ritual that accompanies self-injection. However, whilst this is briefly mentioned, the authors make little attempt to deal with the subject of needle fixation. Sue et al. explain, in detail, the ritual of injection in the context of treating addicts. The conceptual leap from the idea of needle habit prevalent in Sue et al.'s claims, to the concept of 'needle fixation' in the recent work of McBride, Pates and Arnold is profound.

Jen-chieh Tsai's article, From Need to Needle: the Cult of Addiction in William Burroughs, reveals a significant relationship with my work, my emphasis is on formulating a theory of needle fixation, a concept to which Tsai does not refer. Additionally, whilst Tsai seems to speak against the self-medication hypothesis by emphasizing the addicts' use of and relationship with the needle, he also seems compelled to incorporate it into his theory. And whilst he seems to deal with Loose and the jouissance provided by the needle his theory, while claiming to bring addiction into the realm of the symbolic, lacks an extensive extrapolation of Lacan's mirror-stage: "The euphoria experienced by Lee returns one to Loose's definition of addiction: it pertains to the act of administration to execute a certain economy and distribution of pleasure and jouissance" (Tsai, 2006, p.10). Here, as in the rest of the article, he grapples with the issue of administration only to return to the concept of self-medication before finally merely restating a component of Loose's thesis, "namely, through self-medication, an individual regains feelings of reciprocity, by which self and other engage in the triangular dialectic and the subject is somehow able to live on, with minimalism of pain" (Tsai, 2006, p.10). This characterization of Loose makes him sound like a self-medication hypothesist. Whilst Loose ultimately reverts to the dominant self-medication hypothesis, I believe his discussion of Lacan's mirror stage and its connection with addiction provides a far more compelling explanation for intravenous use and forms the foundations for a theory of needle fixation. Whilst this does not appear to be Tsai's 
intention, he certainly sets out to argue against the dominant emphasis on substance encompassed in the discourse on addiction, and I share his view. However, he emphasizes the toxicity in Loose and, whether this toxicity exists in the realm of the physical or the symbolic it gives the appearance of self-medication. That is, Tsai claims that the needle, because of its symbolic value, self-soothes in a way that the selfmedication hypothesis says that heroin self-soothes. I also use Loose's theory to explain needle use or 'administration', however my emphasis is on the mirror stage component of Loose's theory and a fixation at this unconscious stage. Tsai seems more concerned with how administration or injection self-soothes the trauma at the mirror-stage, though he does not mention the mirror stage. This, despite it being fundamental to Loose's addiction theory and Lacan's concept of jouissance, both of which he discusses at length. I will use Loose's theory in terms of the mirror stage, emphasizing Lacan's discussion of the prop of the parental other, proposing a fixation at this stage as the cause for compulsive injection thus answering the concerns of Fraser et al. regarding Pates and McBride's theory of needle fixation.

Psychoanalysis seems primarily caught up in the chemical hypothesis with regard to the more general problem of addiction, as opposed to needle fixation. The assumption that the body is nothing but a chemical entity provides the foundation for imagining it might be in need of chemical medication, whether from the self, as in the self-medication hypothesis, or from a medical authority. However not all psychoanalysts take this approach. Mitchell May, for instance, attributes addiction to the addict's fear of intimacy and subsequent transference to the substance: "It [addiction] signified the fear of intimacy based on deep-seated distrust, which the analyst must be able to tolerate with a sense of hope that it will lead from a non-human to a human relationship" and further concludes that "cocaine use is a substitute for a human relationship, a transference" (May, 1991, p. $10)$.

When McBride, Pates and Arnold identify the three elements present at the injection site as body, substance and mechanism, they pave the way for a vital and unexplored area of interest for psychoanalysis: the needle (McBride, Pates \& Arnold, 2005). This represents a departure from the dominant self-medication hypothesis, the primary focus of which is the substance and the chemical hypothesis of the body. This chemical hypothesis is adhered to by May, Khantzian and many others approaching the subject, one notable exception being Rik Loose. For whilst May, for example, identifies the addict's nonhuman relationship with cocaine, this non-human relationship is assumed to be based on attraction to the substance not the mechanism of the needle. By locating the source of addiction at Lacan's mirror-stage of development, which is a specific, unconscious moment, Loose departs from previous psychoanalytic thinking. Nevertheless, even Loose proposes a kind of self-medication hypothesis, albeit rather abstract, by suggesting that addiction medicates the dissatisfaction from the insufficient orgasm of masturbation. Lacan classifies jouissance as a form of satisfaction akin to the satisfaction of a drive (Lacan, 1959). This understanding of the word extends beyond mere satisfaction. The satisfaction of a sexual drive, for example, is completely distinct from the satisfaction one feels from a good meal. The jouissance of the needle refers to the needle as a means "of getting off...however clean or dirty" (Fink, 1997, p. 9). Pates and McBride's research reflects this notion of jouissance. They quote one addict as saying of the needle, that "without it, life would be unsupportable" (McBride, Pates \& Arnold, p. 48). Moreover, in this article, I claim that the satisfaction an addict derives from compulsive injection finds its origins at the unconscious mirror stage of development and that the kick addicts get 
from the needle is caused by a fixation at this stage. The addicts in Fraser et al.'s study volunteered the term 'needle fixation' (Pates \& McBride, 2004). This term is then used by McBride and Pates to further the idea of needle fixation and elicits a 'response' from Fraser et al., in which they argue that fixation is not the correct term to describe the phenomenon, that it is a psychoanalytic term and therefore they say, it has no currency in the current debate. My research will involve an exploration of the term 'fixation', addressing this question whether needle fixation is a genuine phenomenon with an unconscious cause. In order to do this, I will use the work of Rik Loose in Subject of Addiction and Freud's use of the term 'fixation' as developed in his Three Essays on Sexuality. Central to Loose's work is Lacan's notion of jouissance. He draws a connection between jouissance and addiction. I will use this notion of jouissance to formulate a psychoanalytic theory of needle fixation, a theory that is absent from the current discourse, both in relation to addiction theory and psychoanalysis.

\section{Fixation and Needle Fixation}

In Injecting Illicit Drugs Andrew McBride describes needle fixation as the compulsion to inject regardless of substance (McBride, 2005). The descriptive term used here has been rejected on the basis that so called 'needle fixation' is not a fixation in the psychoanalytic sense. Fraser et al., for example, question the use of the term 'fixation', citing its psychoanalytic origins as arrested development at an unconscious stage and claim the term has no value in describing compulsive injection (Fraser et al., 2004). I will present a theory of needle fixation, using Freud's definition of the term 'fixation' to argue that the term 'needle fixation' describes a fixation on the libidinal content at the mirror stage of development. That is, needle fixation, the repeated puncturing of the skin and veins by injecting drug users is the imaginary consummation of the libidinal encounter with the parental other at the mirror stage.

In his Three Essays on the Theory of Sexuality, Freud discusses, or at least refers to, fixation at length. In one of these discussions he states:

Many persons are detained at each of the stations in the course of development through which the individual must pass; and accordingly, there are persons who never overcome the parental authority and never, or very imperfectly, withdraw their affection from their parents. (Freud, 1962, pp. 617-618)

Hence, fixation represents a failure in the human subject to move through a particular unconscious stage. The question remains whether addiction to the needle can be accounted for in terms of this definition of fixation. A disturbance at the mirror stage that, for Loose causes addiction and, for me, causes needle fixation is related to the libidinal content to which Lacan fleetingly refers. The presence of the mother becomes a third party at the mirror stage. The players in the drama of the mirror stage, as it is described by Lacan, include the child, the image in the mirror and the mother, who acts as a prop and holds the child up to the mirror. The presence of the mother is further problematised by her symbolic value and the child's unconscious sexual drive toward the figure of the 
mother. In the development of the ordinary child, this unconscious stage is merely one of life's unfolding developments. However, as Freud explicitly states, we can become stuck at one of the many unconscious stations in life and this is how he describes the phenomenon of unconscious fixation. Loose, in his book Subject of Addiction, claims that addiction is caused by a disturbance at the mirror stage. Perhaps the mother is overbearing. Or perhaps the child confuses his or her own mirror image with image of self and mother or prop, holds the child and appears in the image in the mirror. The human subject's fixation at this unconscious moment causes him/her to seek out activities that satisfy these unconscious drives.

I claim that one such activity is compulsive self injection with the medical needle, recently characterised in drug and alcohol circles as needle fixation. The criticism of needle fixation is that it appears to have no unconscious cause. I claim that an unconscious fixation on the libidinal content at the mirror stage creates a disturbance in the addict with the will to compulsively inject and provides this unconscious content. It is the missing piece of the jigsaw, as it were. The traditional argument supposes that the addict compulsively injects for the orgasmic rush of an immediate and excessive injection of the substance into the body using the hypodermic needle (Brechter, 1972). Theorists such as Brechter claim that addiction to the needle is, in fact, addiction to the substance. If Brechter is correct, then it seems fixation is not an appropriate term and this perhaps explains why some theorists reject its use in this context. The interplay between reality and description here is the central point of interest. The question of whether what we call needle fixation is indeed a fixation is not a frivolous or pedantic one. For the language we use to describe a phenomenon affects the way in which we understand it and treat it. By describing compulsive injection as needle fixation, we risk the phenomenon being neglected by drug and alcohol counsellors and/or theorists. Part of the problem with the use of the term 'needle fixation' is not that it does not correctly describe the phenomenon to which it refers but that there is a poverty of understanding when it comes to terms such as fixation, sourced from the language psychoanalysis but misused in other fields such as drug and alcohol.

Brechter's theory may explain the desire to inject or the addicts' choice to use the needle as a means of administration over other means. However, it does not explain the recently identified compulsion to inject regardless of substance (Pates \& McBride, 2007). The compulsive nature of the behaviour, the desire to repeat the act of injection, is not accounted for by the association with substance, which is the genesis of psychoanalysis' self-medication hypothesis and other theories of addiction that see needle use in terms of the administration of the drug. Thus, the compulsive, repetitive injection appears to provide the addict with a satisfaction that is independent of substance. Hence, the needle and its interaction with the body have been sexualized by some users and this has little, if anything, to do with the substance being injected. It is here that the term 'fixation' is appropriate. For I claim that the compulsion is caused by arrested development at the mirror stage and a libidinal encounter with the parental other. If this is what the addict is unconsciously experiencing when he/she injects, then the term 'fixation' is most certainly appropriate and the problem of language from psychoanalysis in Drug and Alcohol is considerably diminished. 


\section{Perversion and Compulsive Injection}

What is the needle fixator experiencing when he/she injects? What are we describing when we say 'needle fixation'? This idea of needle and body taking precedence over substance removes one of the three elements identified at the injection site by McBride, Pates and Arnold in Injecting Illicit Drugs (2007). The mechanism and the body are the sources of enjoyment for addicts studied by these authors. This seems to require a discussion of the body. What is happening in the body of the segment of the population of intravenous drug users I have labelled the needle-fixators? Freud (1905) discusses erotogenic zones on the body. These zones are sources of pleasure that have been unconsciously eroticized and form the foundation for various compulsive activities such as thumb-sucking. In the case of thumb-sucking, the mouth has been eroticized.

In the perversions which claim sexual significance for the oral cavity and the anal opening the part played by the erogenous zone is quite obvious. It behaves in every way like a part of the sexual apparatus. In hysteria these parts of the body, as well as the tracts of mucous membrane proceeding from them, become the seat of new sensations and innervating changes in a manner similar to the real genitals when under the excitement of normal sexual processes (Freud, p.27).

With this in mind, how might we understand needle fixation and is it an appropriate term to describe compulsive injection? Are we using the correct language when we talk about needle fixation? Needle fixation is the eroticisization of the activity of self-injection, regardless of substance. The disassociation of the sexual instinct provides the injecting drug user with a new location for pleasure, the injection site on the body, the needle itself behaving in every way "like a part of the sexual apparatus" (Laplanche \& Pontalis, 1973, p.162). Further to this, various recently published health journals and users' guides warn users not to inject repeatedly in the same vein (NCHRC, 2014). This implies that, without this warning, users otherwise would inject into the same vein. Indeed, many of the health problems associated with intravenous drug use, such as collapsed veins, are caused by this single tendency. Therefore, is the compulsion to inject an eroticization of the injection site on the body? Perhaps this represents an attempt by the intravenous drug user to create a new location for pleasure on the body, a new orifice by which the addict might satisfy an unconscious drive. It appears to be common among the particular group or segment of the population of addicts said to be suffering from needle fixation.

Needle fixation is not only the compulsion to inject but an eroticization of the injection site on the body, evidenced by the failure of the addict to rotate the injection site and it has an unconscious cause: the traumatic unconscious experience with the parental other at Lacan's mirror stage (Lacan, 1976). Compulsive self-injection represents a consummation of this libidinal encounter. The compulsion to inject regardless of substance, experienced by a portion of the addict population, is a symbolic satisfaction of this infantile sexual drive. This assigns needle fixation to the realm of the unconscious and explains the desire to inject regardless of substance. Therefore, I argue that needle 
fixation is not only a real and genuine phenomenon experienced by injecting drug users with a lust for the needle, it is an unconscious fixation best described using the language of psychoanalysis. If we treat compulsive injection as a conscious desire for the orgasmic rush from the intake of an excessive dosage of substance, then we ignore the word 'fixation' and the unconscious drama it potentially describes. By viewing needle fixation as a fixation on the libidinal content at the mirror stage, we not only create revelations for alcohol and drug treatments, we also explore the potential for language from psychoanalysis to inform our understanding in other areas.

\section{Libidinal Attachment to the Needle}

The libidinal encounter with the parental other at Lacan's mirror stage is the unconscious fixation of needle fixation (Lacan, 1976). This libidinal content explains the almost irrational connection with the needle, described by addicts in the research conducted by McBride Pates and Arnold. In the case of needle fixation, the libido has been transferred from the erogenous regions to new locations for pleasure, the injection site where addicts are identified as injecting into the same spot. It is this libidinal attachment to the arm and the needle, the fluid and the blood that has been missing from the current debate, where needle fixation is referred to as the act of compulsive injection, whether it has an unconscious cause or not.

I claim that the act of compulsive injection is merely symptomatic of a deeper, unconscious drive. This explains recent research that has identified a particular way of conducting relationships specific to addicts: "such relationships are characterized by parental models of self-control and emotion regulation" (Ries et al., 2009, p. 64). By identifying a mode of relating, specific to the addict, these recent medical researchers are identifying a phenomenon prevalent in the process of treating addicts with psychoanalysis, that the relationship is not apriori as it is in ordinary psychotherapy (Loose, 2002). Combining this tendency, common to addicts including needle addicts, with psychoanalytic research and McBride and Pates' data, I claim that the addict is satisfying an unconscious drive by the act of compulsive injection. The compulsion of compulsive injection resembles masturbation, which Freud described as the greatest of all addictions. It is the compulsive nature of masturbation that connects it with needle fixation or an addiction to injecting. The insufficient orgasm achieved through the universal compulsion to masturbate leaves the human subject with "surplus energy...released in laughter, crying and other pathologies of everyday life" (Loose, 2002, p. 72). Loose seems to argue that addiction to substances and other compulsions are attempts to achieve the complete satisfaction that masturbation fails to provide. Expanding on this, I propose that the act of injection for some needle using drug addicts constitutes a form of masturbation. It is an attempt to achieve complete satisfaction which cannot be provided by masturbation because of the disturbance at the mirror stage at which the needle fixator is fixated.

What is important about the notion of needle fixation is not the repeated puncturing of the skin, as McBride, Pates and Arnold claim, but the fact that for the intravenous drug user, "libido has attached itself [to the needle and it produces a particular mode of satisfaction" (Laplanche \& Pontalis, 1973). This libidinal content, identified by Laplanche and Pontalis as the definition of fixation gives substance to the ethnographic descriptions of 'compulsive self injectors' offered by recent addiction theorists (McBride, Pates \& Arnold, 2005). It also offers insight into the "incestuous and masturbatory activities' that 
are taking place at the site of injection" (Loose, 2002, p. 83). The libidinal attachment to the needle can be traced back to the mirror stage where Lacan describes the prop, the parental other who holds the child to the mirror and becomes integrated into the child's self-image and the needle, rather than the world becomes the source of self-completion. This can explain the disputed notion of needle fixation. I argue that compulsive injection, particularly, can be traced back to a disturbance at this unconscious stage.

I contend that needle fixation, as opposed to addiction generally, is located at the unconscious moment of the mirror stage. The needle is the third party during the mirror stage of development, the parental other, who helps and encourages the child to recognize its image in the mirror "a third element that can function as a reference point" (Loose, 2002 , p. 26). The existence of this reference point, coupled with the idea that the organism is in bits and pieces creates a symbolic matrix that "precipitates the formation of the 'I' before this 'I' is able to identify with psychically processed sexual drives" Loose, 2002, p.26). This is where the possibility of a relationship with the needle is established and the self-completion it provides in the addicts identity. Addicts quoted by McBride, Pates and Arnold say of the needle: "Without it, life would be unsupportable" (McBride, Pates \& Arnold 2007, p. 48). Fraser et al. claim that this fact alone does not warrant the use of the term 'fixation'. What is required is an unconscious explanation and that is the concern of my thesis. The experience of self-injection, for example, can be explained by appealing to Lacan's jouissance. This is why it excites both enjoyment and repulsion in the user and the other. Examples of this enjoyment and repulsion can be found in McBride, Pates and Arnold. Self-injectors describe an enjoyment elicited from "self-inflicted pain...they talk as though self-punishment were a pleasure" (McBride, Pates \& Arnold 2007, p. 51). Some of Burroughs' descriptions of injection barely disguise the metaphor with intercourse, 'Ike's gentle finger' and 'Ike was good.' The simultaneous existence of enjoyment and repulsion assigns needle fixation to the realm of jouissance.

Non-medical self-injection represents a fixation, an activity in which "the subject seeks out a particular activity or else remains attached to certain properties of the object whose origin can be traced back to some specific occasion in the sexual life of his childhood" (Laplanche \& Pontilus, 1973, p. 163). This specific occasion is the libidinal encounter at the mirror stage of development where addiction, as well as anxiety and aggression are located. The problem with the current debate is that it seems only to deal with the notion of injection, or compulsive injection, with regard to the construction of a theory of needle fixation. ${ }^{3}$ It addresses the problem of the needle and ignores the fixation of the user, who reveals a preference for injecting. This is primarily caused by a disproportionate emphasis on substance, the origins of the self-medication hypothesis and Brechter's theory that addicts inject for the orgasmic rush brought about from the rapid and efficient administration of substance. A compelling recent example that questions this view is the practice of femoral injecting, where the user repeatedly injects into the femoral area, the enjoyment seeming to be independent of substance and overtly concerned with the enjoyment of the activity of repeated injection (Australian Injecting and Illicit Drug Users League, 2006).

\footnotetext{
${ }^{3}$ McBride, Pates and Arnold, Injecting Illicit Drugs.
} 


\section{Conclusion}

In conclusion, needle fixation is caused by a disturbance at the unconscious mirror stage of development. It is indicative of an overdependence on the parental other and the mirror stage, a fixation on the libidinal encounter. The needle, for the needle-fixator, is not merely a means of administering a drug, it provides the sense of self-completion usually assumed to be the function of substance to self-medicate, particularly in the field of psychoanalysis (Loose, 2002). This self-completion is achieved by a sexualization of the needle and the injection site on the body, the creation of a new orifice, and it has an unconscious cause. This unconscious cause is a disturbance at the mirror stage and compulsive self-injection is a form of masturbation, fantasising intercourse with the parental other. This departs from the conventional understanding of the term, which is at issue for Fraser et al. What this essentially means that the argument over needle fixation is one about language, over who owns such a term, who is entitled to use it and the conditions that must exist for the term to be used as a description. In order to have the phenomenon of needle fixation recognised and treated by a resistant establishment, we must not only speak in the language of psychoanalysis, we must reinterpret the experience such language describes. What is the needle? What does it mean? Why do I feel compelled to use it? If it is a fixation, it must have an unconscious cause. In this paper, I have built on the recent work of Rik Loose on addiction, using Lacan's mirror stage as a possible unconscious point at which the 'compulsive injector' is 'detained. By doing this, I am conforming to Freud's definition of "fixation" and the psychoanalytic language that will allow such a compulsion to be recognised as having an unconscious cause.

\section{Acknowledgment}

In this work, I acknowledge the significant contribution of my Masters mentor and supervisor, Associate Professor Russell Grigg. 


\section{References}

Australian Injecting and Illicit Drug Users League (2006). Femeral Injecting: A guide to injecting in the groin using the femeral vein. Retrieved from http://aivl.org.au/database/sites/default/files/Femoral\%20Injecting\%20Resource.pdf

Becker, H. (1963). Outsiders: Studies in the sociology of deviance. New York, NY: The Free Press.

Brechter, E. M. (Ed.) (1988). Licit and illicit drugs: The Consumers Union report on narcotics, stimulants, depressants, inhalants, hallucinogens, and marijuana including caffeine, nicotine, and alcohol. Boston, MA: Little Brown and Company.

Freud, S., \& Ferenczi, S. (1914-1919). The correspondence of Sigmund Freud and Sandor Ferenczi, Volume 2. Cambridge, MA: Harvard University Press

Burroughs, W. (1953) Junkie: Confessions of an unredeemed drug addict. New York, NY: Penguin Books.

Grayerholz, J., \& Silverberg A. D. (2000). Word virus: The William S. Burroughs reader. New York. Grove Press.

Byck, R. (Ed.) (1972). Cocaine papers: Sigmund Freud. New York, NY: Stonehill.

Fink, B. (1997). A clinical introduction to Lacanian psychoanalysis. Cambridge, MA: Harvard University Press.

Fraser, S., Hopgood, M., Brenner, S., \& Treloar C. (2004). Needle fictions: Medical constructions of needle fixation and the injecting drug user. Addiction Research and Theory, 12, 67-76.

Fraser, S., Hopgood, M., Brenner, S., \& Treloar C. (2005). The power of naming: a reply to McBride and Pates. Addiction Research and Theory, 13, 403-404.

Masson, J. M. (1985) (Ed.). The complete letters of Sigmund Freud to Wilhelm Fliess, 1887-1904. Cambridge, MA: Harvard University Press.

Freud, S. (1961). Three essays on the theory of sexuality (J. Strachey Trans.). New York, NY: Basic Books. (Original work published 1905).

Freud, S. (1913). The interpretation of dream (A. A. Brill, Trans.) New York, NY: The Macmillan Company. (Original work published 1900).

Rezza, G. Dorrucci, M. Filbeck, U. Serafin, I. (1992). Estimating the trend of the epidemic of drug use in Italy. British Journal of Addiction, 87, 1643-1648.

Hopper, E. (1976). A psychoanalytical theory of drug addiction: Unconscious fantasies of homosexuality, compulsions and masturbation within the context of the traumatogenic processes. International Journal of Pscho-Analysis, 76, 1121-1142.

Howard, J. \& Borges, P. (1971) Needle sharing in the Haight: Some social and psychological functions. Journal of Psychedelic Drugs, 4, 71-80.

Nyrop, K. (2003). An Ethnographic Comparison of Public Venue Drug Markets in Two Seattle Neighbourhoods. Report prepared for the Law Offices of the Public Defender April 2003.

Page, J. B. \& Smith, P. C. (1990) Venous envy: The importance of having functional veins. Journal of Drug Issues, 20, 291-308.

Khantzian, E. J., Albanese, M. J., Ruffins, S., Robins, C. E., Suh, J. (2008). Selfmedication hypothesis connecting affective experience and drug choice. Psychoanalytic Psychology, 25, 518-532.

Klein, M. (1957), Envy and gratitude. A study of unconscious sources. New York, NY: Basic Books.

Lacan, J. (1992). The ethics of psychoanalysis 1959-60, Book VII. London, UK: Routledge.

Lacan, J. (2004). Ecrits (R. Grigg \& B. Fink, Trans.). New York, NY: W. W. Norton. 
Laplanche, J. \& Pontalis, J. B. (1973). The language of psychoanalysis (D. NicholsonSmith, Trans.). New York, NY: W. W. Norton.

Latimer, D. \& Goldberg, J (1985) Flowers in the blood: A history of opium use. New York, NY: Franklin Watts.

Levine, D. J. (1994). Needle freaks: Compulsive self injection by drug users. American Journal Of Psychiatry, 131, 297-300.

Loose, R. (2002) Subject of addiction. London, UK: Karnac Books.

Manderson, D. (1995). Metamorphoses: Clashing symbols in the social construction of drugs. Journal of Drug Issues, 25, 779-816.

May, M. (1991). Observations on countertransference: Addiction and treatability. In A. Smaldino (Ed.), Psychoanalytic approaches to addiction (pp. 1-13). New York, NY: Knopf.

McBride, A., Pates R. \& Arnold K. (2005). Injecting illicit drugs. Oxford, UK: Blackwell Publishing Limited.

Miller, J. (2002). Heroin addiction: The needle as transitional object. Journal of The American Academy of Psychoanalysis, 30, 165-172.

Nyamuryekung'e K. Laukamm-Josten U. Vuylsteke B. Mbuya C. Hamelmann C. Outwater A. Steen R. Msauka A. Dallabetta G. (1997). STD services for women at truck stop in Tanzania: evaluation of acceptable approaches. East Africa Medical Journal, 74, 343-347.

Pates R., \& Gray N. (2009). The development of a psychological theory of needle fixation. Journal of Substance Use, 14, 202-206.

Pates, R., \& McBride, A. (2005). Needle Foucation: Deux ou trois choses que je sais de Pica Manie (with apologies to Jean Luc Godard). Addiction Research and Theory, 13, 395-402.

Ries, R., Fiellin, D, Miller S., \& Saitz, R. (Eds.) (2009) Principles of Addiction. American Society of Addiction Medicine, 4, 911-924.

Rowe, J. (2009). The feel of the steel: Addressing the obsession to inject. Working Paper Series, The Centre for Applied Social Research, RMIT, Melbourne.

Sue, D., Sue, D. W., \& Sue, S. (2006). Understanding abnormal behaviour. New York, NY: Houghton Mifflin Company.

Tsai, J. (2006). From need to needle: The cult of addiction in William Burroughs' Junky', NTU Studies in Language and Literature, 1, 1-24.

Valentine, K., \& Fraser, S. (2008). Trauma, damage and pleasure, International Journal of Drug Policy, 19, 412.

Winnicott, D. W. (1953). Transitional objects and transitional phenomena. A study of the first not-me possession. International Journal of Psycho-Analysis, 34, 89-97. 